\title{
Pneumoconiosis in Cornish china clay workers
}

\author{
P D OLDHAM
}

From the MRC Pneumoconiosis Unit, Llandough Hospital, Penarth, S Glamorgan CF6 1XW, UK

\begin{abstract}
A radiological survey of men employed in the china clay industry in Cornwall was carried out in 1977. Each man completed a short questionnaire on respiratory symptoms and smoking habits, his occupational history was determined, and his forced expiratory volume and vital capacity were measured. The radiographs were read independently by three observers, using the 1980 ILO classification. Of the 1728 men in the study, 23 had had dust exposure elsewhere, mostly in tin mining, and were excluded. Readings of the radiographs were available for 1676 men: $77.4 \%$ were within category $0,17.9 \%$ in category 1 , and $4.7 \%$ in categories 2 and 3 . In 19 men $(1 \cdot 1 \%)$ one or more readers recorded the presence of a large shadow and read it as complicated pneumoconiosis, but in only four men were the readers unanimous. Every job recognised as dusty contributed significantly to the amount of simple pneumoconiosis, and in two jobs the conditions were such that the average worker would reach category 2 in a working lifetime. Smoking appeared unrelated to the radiographic appearance. Vital capacity showed a significant reduction with increasing amount of pneumoconiosis, but not, when this was allowed for, on the duration of exposure in any of the job categories. In addition it depended, as would be expected, on smoking. The effect of one category increase in pneumoconiosis was equivalent to 4.1 years of age in smokers, 3.9 years of age in ex-smokers, and 5.4 years of age in non-smokers. Forced expiratory volume did not decline significantly with amount of pneumoconiosis, so that FEV\%VC showed an increase, though not to a significant extent. No relationship between symptoms and past exposure was detected.
\end{abstract}

In 1964 Sheers $^{1}$ reported that $9 \%$ of 553 Cornish china clay workers who had been exposed to kaolin dust in drying plants for more than five years showed radiological signs of pneumoconiosis. The distribution of the categories of pneumoconiosis was unusual, with few men in category 1 and almost equal numbers in categories 2 and 3 and with complicated pneumoconiosis. In 1977 the largest producers of china clay in Cornwall offered a chest radiograph and tests of lung function to those of its employees engaged in potentially dusty occupations. This new survey offered an opportunity to confirm Sheers's findings and to explore the relationship of changes in lung function to exposure and to radiological pneumoconiosis.

\section{Data}

The questionnaire, apart from giving works numbers, date of birth, and height, asked if the subject

Received 7 July 1982

Accepted 16 August 1982 had ever had a chest or heart illness, whether he had chronic cough and phlegm, whether he found himself short of breath on hills and on the level in comparison with others of his own age, and whether he was or ever had been a smoker, and, if so what was his consumption of cigarettes and other forms of tobacco.

Lung function was tested by a single Vitalograph tracing, from which the forced expiratory volume in one second $\left(\mathrm{FEV}_{1}\right)$ and the forced vital capacity (FVC) were derived.

The chest radiographs were taken by the NCB Radiological Service, and were separately read by PC Elmes, JC Gilson, and G Sheers, using the 1980 ILO international classification of radiographs. ${ }^{2}$

The various different jobs were classified into 11 groups (table 1). This is an extension of the classification used by Sheers. Each man's employment history was then classified by the calendar years spent in these classes. In addition, periods spent outside the industry (jobs $M, N, P, R$ ) with a possible dust hazard were recorded. Only 23 of the 1728 men had had such exposure (most of them in 
Table 1 Classification of jobs

\begin{tabular}{ll}
\hline A & Pressmen, firemen, and kilnmen before 1954 \\
B & Millers, baggers, and loaders before 1954 \\
C & Pressmen, firemen after 1954 \\
D & Millmen and baggers after 1954 \\
E & Loaders and banksmen after 1954 \\
F & Calciner employees \\
G & China stone-mills, drys, crushers, and grinding \\
H & Pit operatives and transport workers \\
J & Dock workers \\
K & Sundries-little china clay dust \\
L & No dust \\
M & Farmers \\
N & Slate quarries \\
P & Tin miners \\
R & Asbestos working \\
\hline
\end{tabular}

tin mining), and these men were excluded from the analyses.

The remaining 1705 men, all of whom had occupational histories recorded, form the basis of the analyses that follow. Some items of information were missing in 213 men; table 2 shows how these were distributed. Each analysis was based on every man for whom the relevant information was obtainable.

\section{Results}

\section{RADIOLOGICAL FINDINGS}

Table 3 shows how the three readers of the radiographs classified them according to the profusion of the small opacities characteristic of simple pneumoconiosis. Readers A and B give quite similar results, whereas reader $\mathrm{C}$ distributes the radiographs differently below category $1 / 0$, reading many more in the "absolutely normal" category $0 /-$ and the categories $0 / 1$ and $1 / 0$, where uncertainty between adjacent categories was felt. Combining all the readings (fig 1), $77.4 \%$ were in category 1 , and $4.7 \%$ in categories 2 and 3 . The small opacities were predominantly read as rounded, usually as type q. Irregular opacities were recorded as well as rounded in about a quarter of the readings; pure irregular opacities were rare.
Table 3 Distribution of the chest radiographs by amount of simple pneumoconiosis

\begin{tabular}{|c|c|c|c|c|c|c|}
\hline & \multicolumn{6}{|c|}{ Reader } \\
\hline & $A$ & & $B$ & & $C$ & \\
\hline$(0 /-$ & 19 & & 18 & & 133 & \\
\hline$(0 /()$ & 1200 & & 1156 & & 677 & \\
\hline ()/1 & 134 & & 185 & & 368 & \\
\hline Category () & & 1353 & & 1359 & & 1178 \\
\hline $1 / 0$ & 64 & & 111 & & 203 & \\
\hline $1 / 1$ & 164 & & 87 & & 169 & \\
\hline $1 / 2$ & 22 & & 26 & & 54 & \\
\hline Category 1 & & 250 & & 224 & & 426 \\
\hline $2 / 1$ & 15 & & 29 & & 30 & \\
\hline $2 / 2$ & 48 & & 33 & & 30 & \\
\hline $2 / 3$ & 4 & & 23 & & 4 & \\
\hline Category 2 & & 67 & & 85 & & 64 \\
\hline $3 / 2$ & 1 & & 3 & & 2 & \\
\hline $3 / 3$ & 5 & & 5 & & 3 & \\
\hline $3 /+$ & - & & - & & - & \\
\hline Category 3 & & 6 & & 8 & & 5 \\
\hline No reading & - & & - & & 3 & \\
\hline Total & & 1676 & & 1676 & & 1676 \\
\hline
\end{tabular}

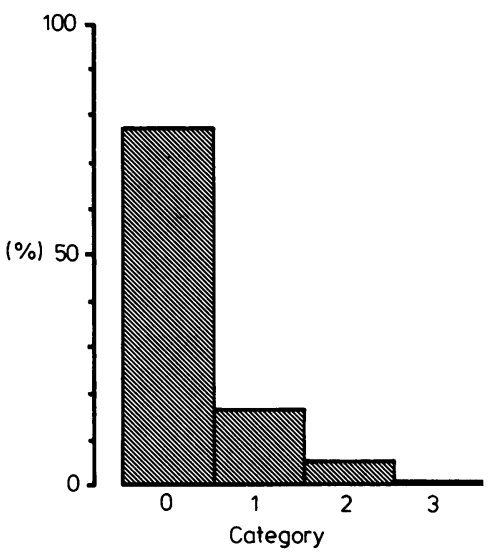

Fig 1 Distribution of radiological readings by major category.

In 19 men $(1 \cdot 1 \%)$ one or more readers recorded the presence of a large shadow and read it as complicated pneumoconiosis. In only four of these were the readers unanimous; in the others one or more

Table 2 Missing items of information in 213 men

\begin{tabular}{|c|c|c|c|c|}
\hline & & $X$-ray reading & None & Total \\
\hline Questionnaire answered & $\begin{array}{l}\text { Lung function measured } \\
\text { Not measured } \\
\text { Total }\end{array}$ & $\begin{array}{r}1492 \\
123 \\
1615\end{array}$ & $\begin{array}{r}26 \\
2 \\
28\end{array}$ & $\begin{array}{r}1518 \\
125 \\
1643\end{array}$ \\
\hline Not answered & $\begin{array}{l}\text { Lung function measured } \\
\text { Not measured } \\
\text { Total }\end{array}$ & $\begin{array}{r}57 \\
4 \\
61\end{array}$ & $\begin{array}{l}1 \\
0 \\
1\end{array}$ & $\begin{array}{r}58 \\
4 \\
62\end{array}$ \\
\hline Total & $\begin{array}{l}\text { Lung function measured } \\
\text { Not measured } \\
\text { Total }\end{array}$ & $\begin{array}{r}1549 \\
127 \\
1676\end{array}$ & $\begin{array}{r}27 \\
2 \\
29\end{array}$ & $\begin{array}{r}1576 \\
129 \\
1705\end{array}$ \\
\hline
\end{tabular}


readers classified the shadow as due to other disease or did not record it. Of the four unanimous cases, three had worked for more than 25 years as a pressman, fireman, or kilnman. The other had worked for 37 years with china stone.

Interestingly, 15 of the 23 men with dust exposure outside the china clay industry were read as having signs of pneumoconiosis by one or more readers. Thirteen of them had worked in tin mining, two in slate quarrying. Though it is not certain that this external exposure produced the radiological changes, it is clear how necessary it is to eliminate men with mixed exposures if a true assessment of the effects of china clay is to be achieved.

For more detailed analysis of the readings of the radiographs, the cumulative distributions of the readings by major categories were plotted, on transformed scales, and straight lines fitted by an iterative maximum likelihood procedure. The location of the subcategories was then established by interpolation, and the midpoint of each used as a score for a reading of that subcategory. The method is described by Oldham. ${ }^{3}$ For each man a mean score was derived by weighted averaging of the scores for each observer. Because of the discrepant readings of reader $\mathrm{C}$ a score excluding him was also calculated. The scale for the radiological score is such that the width of category 1 is unity.

The dependence of the radiological scores on the period spent in each of the 11 occupational groups was investigated by multiple regression analysis. Each man's age was also included. The results for the score excluding reader $\mathrm{C}$ were similar to those for the score including him, but the multiple correlation coefficient in each analysis was marginally smaller. Consequently the score for all readers will be used in all that follows. Initially the analysis was carried out separately for non-smokers, ex-smokers, and smokers, but no relationship with smoking was detected. Table 4 shows the regression coefficients of $\log _{e}$ (radiological score) on the 12 variables.

The coefficients fall into three classes. Jobs $D$ and $E$ have coefficients of 0.024 and 0.021 respectively, jobs $\mathrm{A}, \mathrm{B}, \mathrm{C}, \mathrm{G}$, and $\mathrm{J}$ coefficients between 0.012 and 0.016 , and jobs $F, H, K, L$, and $M$ coefficients between 0.001 and 0.005 . To show the practical significance of these regression coefficients, fig 2 shows the regression lines appropriate to individuals beginning exposure at age 15 in a particular job and continuing to age 65 . For instance the line for job $D$ would be $\log _{e}$ (radiological score) at age $\mathrm{A}$ $=-0.866+15 \times 0.009+(\mathrm{A}-15)(0.009+$ $0.024)$.

Thus the average man working in jobs $D$ and $E$ throughout his working life would be expected to
Table 4 Regression coefficients of $\log _{e}$ (radiological score) $\times 1000$ on years of work in 11 jobs and years of age

\begin{tabular}{ll}
\hline $\begin{array}{l}\text { Independent } \\
\text { variable* }\end{array}$ & $\begin{array}{l}\text { Regression coefficient and } \\
\text { standard error }\end{array}$ \\
\hline A & $12 \pm 2$ \\
B & $16 \pm 4$ \\
C & $16 \pm 2$ \\
D & $24 \pm 3$ \\
E & $21 \pm 4$ \\
F & $5 \pm 3$ \\
G & $13 \pm 3$ \\
H & $5 \pm 2$ \\
J & $13 \pm 5$ \\
K & $4 \pm 1$ \\
L & $2 \pm 1$ \\
Age & $9 \pm 1$ \\
\hline
\end{tabular}

*The letters $\mathrm{A}$ to $\mathrm{L}$ stand for the occupational groups as previously shown.

reach category 2 , the compensatable level of pneumoconiosis, as would a proportion of men in jobs $B$ and C. Jobs F, H, K, L, and M produce little more pneumoconiosis than was seen associated with age alone (possibly reflecting undetected dust exposure or non-specific effects of aging).

The scatter about these regression lines is large, about $46 \%$ (logarithmic SD $(0 \cdot 3771)$ ), so that they should be regarded as giving no more than an indication of the order of magnitude of the risks of different jobs. The multiple regression accounted for $30 \%$ of the variance of the radiological scores.

The use of the number of years worked in each job as a measure of exposure would be appropriate for an inert dust remaining indefinitely in the lung without producing a progressive reaction. A dust

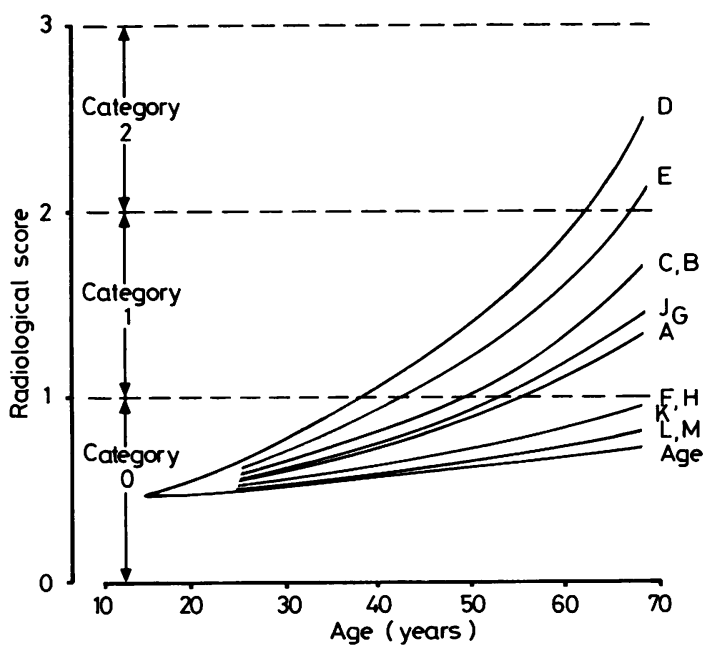

Fig 2 Predicted amount of radiological pneumoconiosis produced by pure exposure in 11 china clay jobs. 
Table 5 Regression coefficients of $\log _{e}$ (radiological score) $\times 1000$ on years of work and residence time

\begin{tabular}{lcc}
\hline Job & \multicolumn{2}{c}{ Regression coefficient (and standard error) on: } \\
\cline { 2 - 3 } & Years worked & Residence time \\
\hline A & $12 \pm 4$ & $-0 \pm 3$ \\
B & $19 \pm 6$ & $-2 \pm 2$ \\
C & $8 \pm 3$ & $11 \pm 4$ \\
D & $18 \pm 4$ & $7 \pm 5$ \\
E & $21 \pm 6$ & $-1 \pm 7$ \\
F & $9 \pm 6$ & $-10 \pm 8$ \\
G & $14 \pm 3$ & $-2 \pm 3$ \\
H & $6 \pm 2$ & $-2 \pm 1$ \\
J & $16 \pm 8$ & $-9 \pm 10$ \\
K & $2 \pm 2$ & $2 \pm 2$ \\
L & $-2 \pm 2$ & $3 \pm 1$ \\
Age & $9 \pm 1$ & \\
\hline
\end{tabular}

producing a progressive reaction would be shown by the amount of pneumoconiosis depending additionally on the lapsed time since exposure, or what has been called the residence time. Introducing the appropriate residence times into the regression equation gave the coefficients in table 5. Here the appropriate equation for a pure exposure in job $G$ for example would be

$\log _{e}$ (radiological score) at age $\mathrm{A}$

$=$ constant $+15 \times 0.009+(\mathrm{A}-15)(0.009+$

$0.014) .+($ present age $-A) \times(-0.002)$

The coefficients for "years worked" differ from those in table 4 because they now indicate the estimated effect of a year's exposure at a fixed number of years ago.

Allowing for residence time made no material improvement in the proportion of variance accounted for, but for most occupations the dependance on residence time was negative. This suggests that a year's exposure in a particular job produced less radiological effect if it was long ago than if it was recent. This could be either because the radiological shadows clear with time, or because dust conditions in the same job varied at different times in the past. Fitting a model that incorporated the diminution of radiological pneumoconiosis with the passage of time also produced no improvement but suggested that a half life for the radiological shadows of 25-35 years gave the marginally best fit.

\section{LUNG FUNCTION}

Multiple regression was again used to explore the dependence of vital capacity (VC), forced expiratory volume (FEV), and FEV\% VC on age, radiological score, and years of exposure to each of the 11 occupations. Because of the known dependence of these indices of lung function on smoking habits, separate analyses were carried out for smokers, ex-smokers, and non-smokers. VC and FEV were adjusted for height by dividing by height squared and multiplying by 1.7 squared to produce indices standardised to a height of $1.7 \mathrm{~m} .{ }^{4}$ (The mean height of the group studied was $1.74 \mathrm{~m}$.)

The regression coefficients for $\mathrm{VC}$ are given in table 6 . In each smoking group $\mathrm{VC}$ declines with age and with radiological score, to a similar extent in smokers and non-smokers but far less in exsmokers. There seems to be no consistent dependence on years of exposure. Stepwise elimination of the variables showed that there was no loss of variance accounted for if "years of exposure" was omitted, and the same coefficient on radiological score used in each smoking group. Dependence on age did vary significantly between smoking groups. Table 7 shows the regression coefficients reached after this process of elimination.

VC showed a significant reduction with increasing amount of radiological pneumoconiosis, amounting

Table 7 Regression coefficients for VC, removing insignificant variables

\begin{tabular}{ll}
\hline Age: & \\
Non-smokers & $-0.029 \pm 0.002$ \\
Ex-smokers & $-0.040 \pm 0.003$ \\
Smokers & $-0.038 \pm 0.002$ \\
Radiological score, all smoking groups & $-0.157 \pm 0.040$ \\
\hline
\end{tabular}

Table 6 Regression coefficients of VC (adjusted for height, in ml) on age, radiological score, and years in different occupations

\begin{tabular}{|c|c|c|c|}
\hline & Non-smokers & Ex-smokers & Smokers \\
\hline $\begin{array}{l}\text { Age } \\
\text { Radiol score } \\
\text { A } \\
\text { B } \\
\text { C } \\
\text { D } \\
\text { E } \\
\text { F } \\
\text { G } \\
\text { H } \\
\text { J } \\
\text { K } \\
\text { L }\end{array}$ & $\begin{aligned}-31 & \pm 4 \\
-155 & \pm 88 \\
1 & \pm 9 \\
-1 & \pm 12 \\
2 & \pm 9 \\
-5 & \pm 11 \\
19 & \pm 16 \\
5 & \pm 10 \\
8 & \pm 9 \\
-2 & \pm 7 \\
2 & \pm 17 \\
6 & \pm 5 \\
10 & \pm 6\end{aligned}$ & $\begin{aligned}-42 & \pm 5 \\
-11 & \pm 93 \\
-5 & \pm 8 \\
-15 & \pm 15 \\
2 & \pm 8 \\
-3 & \pm 12 \\
-8 & \pm 17 \\
12 & \pm 12 \\
-8 \pm 9 & \pm 9 \\
1 & \pm 6 \\
-15 & \pm 25 \\
5 & \pm 5 \\
2 & \pm 6\end{aligned}$ & $\begin{array}{rlr}-36 & \pm 3 \\
-199 & \pm 62 \\
3 & \pm 6 \\
-13 & \pm 11 \\
-1 & \pm 5 \\
-8 & \pm 7 \\
17 & \pm 9 \\
1 & \pm 13 \\
-10 & \pm \\
-8 & \pm 4 \\
-5 & \pm 14 \\
0 & \pm 4 \\
-3 & \pm 4\end{array}$ \\
\hline
\end{tabular}


to 0.1571 per category. The lack of dependence on years of exposure, given age and radiological score, suggests that no other occupational factor other than amount of pneumoconiosis needs to be postulated as a cause of loss of lung function.

VC was declining at 0.0381 per year of age in smokers, so that an increase of one radiological category was in smokers equivalent to $4 \cdot 1$ years of age. Non-smokers showed a lower decline of VC, of 0.029 l per year of age, so that for them one radiological category corresponds to 5.5 years of age. In ex-smokers, with the highest loss of VC per year of age, $0.040 \mathrm{l}$, one category corresponded to 3.9 years of age.

Apart from differences of gradient with smoking habits, there were differences in mean. In youth the typical smoker has a larger VC than the typical non-smoker, while those smokers eventually to become ex-smokers have the largest VC of all. Figure 3 illustrates the relative effects of all these factors by showing the $\mathrm{VC}$ against age for each smoking class for men beginning at age 15 in category 0 and remaining there or progressing at a constant rate to be in categories $0,1,2$, or 3 at age 65 . In this figure the fact that usually VC increases with age between 15 and 25 has been ignored, and the slopes (predominantly determined by older men) have been extrapolated to the lowest ages.

Around age 40, where the reference value of VC for height $1.7 \mathrm{~m}$ is $4.36 \mathrm{l}$, all the curves are close together, and the estimated values are near to, or above, the reference value (table 8 ). By age 60 , when the reference value is $3.92 \mathrm{l}$, those with pneumoconiosis are estimated to be on average below it (table 9).

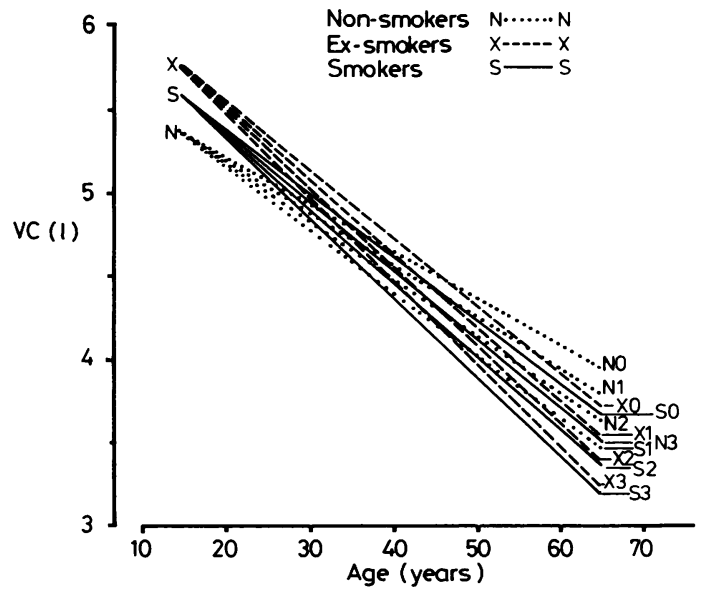

Fig 3 Predicted loss of VC with age, according to smoking habit and rate of development of pneumoconiosis.
Table 8 Estimates of vital capacity for a man of 40, height $1.7 \mathrm{~m}$, according to smoking habit and $X$-ray category

\begin{tabular}{lllll}
\hline \multicolumn{5}{l}{$X$-ray category } \\
\cline { 2 - 5 } & 0 & 1 & 2 & 3 \\
\hline Non-smokers & 4.67 & 4.51 & $4 \cdot 36$ & $4 \cdot 20$ \\
Ex-smokers & 4.74 & 4.59 & 4.43 & $4 \cdot 27$ \\
Smokers & 4.64 & 4.48 & 4.33 & 4.17 \\
\hline
\end{tabular}

Table 9 Estimates of vital capacity for a man of 60, height $1.7 \mathrm{~m}$, according to smoking habit and $X$-ray category

\begin{tabular}{lllll}
\hline \multicolumn{5}{l}{$X$-ray category } \\
\cline { 2 - 5 } & 0 & 1 & 2 & 3 \\
\hline Non-smokers & 4.10 & 3.94 & 3.79 & 3.63 \\
Ex-smokers & 3.93 & 3.77 & 3.62 & 3.46 \\
Smokers & 3.88 & 3.72 & 3.56 & 3.41 \\
\hline
\end{tabular}

Regression analysis of forced expiratory volume (FEV) showed patterns similar to those of VC, but the regression coefficients on radiological score are smaller and do not attain statistical significance. Table 10 corresponds to table 6 and shows these points. Again assuming a dependence on radiological score independent of smoking and no additional dependence on the year of exposure, the loss of FEV is estimated as $0.071 \pm 0.0401$ per category of pneumoconiosis, which, even if real, is of trivial magnitude. Smokers were declining at $0.0371 \mathrm{per}$ year of age, non-smokers at $0.032 \mathrm{l} / \mathrm{year}$, and exsmokers at $0.042 \mathrm{l}$ year.

The results for FEV\%VC are what would be expected from those of FEV and VC. It increased trivially and not significantly with amount of pneumoconiosis at $0.86 \pm 0.62 \%$ per category.

\section{SYMPTOMS}

The questionnaire included only a few questions about symptoms. Of these, cough and shortness of breath are potentially the most relevant.

The complaint of chronic cough varied, as it usually does, with smoking habit: $4 \%$ of non-smokers reported chronic cough, $7 \%$ of ex-smokers, and $23 \%$ of current smokers. There was no convincing evidence of an increasing frequency of cough with amount of radiological pneumoconiosis nor with years worked in different jobs, though among smokers there was a suggestion that years of work on the docks and in milling and bagging was associated with cough.

Only $3 \%$ of the men complained of shortness of breath while walking on the level, and no reliable evidence of whether it could be related to employment was therefore available. Smokers and exsmokers gave $4 \%$ of positive answers, non-smokers $2 \%$. 
Table 10 Regression coefficients of FEV, (adjusted for height, in $\mathrm{ml}$ ) on age, radiological score, and years in different occupations

\begin{tabular}{|c|c|c|c|}
\hline & Non-smokers & Ex-smokers & Smokers \\
\hline $\begin{array}{l}\text { Age } \\
\text { Radiol score } \\
\text { A } \\
\text { B } \\
\text { C } \\
\text { D } \\
\text { E } \\
\text { F } \\
\text { G } \\
\text { H } \\
\text { J } \\
\text { K } \\
\text { L }\end{array}$ & $\begin{aligned}-34 & \pm 4 \\
-167 & \pm 84 \\
6 & \pm 9 \\
-2 & \pm 12 \\
10 & \pm 8 \\
-4 & \pm 11 \\
19 & \pm 15 \\
-2 & \pm 10 \\
13 & \pm 9 \\
4 & \pm 6 \\
-23 & \pm 16 \\
4 & \pm 5 \\
11 & \pm 6\end{aligned}$ & $\begin{array}{r}-42 \pm 5 \\
69 \pm 90 \\
-8 \pm 8 \\
-19 \pm 14 \\
17 \pm 7 \\
-9 \pm 11 \\
-14 \pm 16 \\
11 \pm 12 \\
-15 \pm 9 \\
3 \pm 6 \\
6 \pm 24 \\
5 \pm 5 \\
6 \pm 6\end{array}$ & $\begin{aligned}-37 & \pm 3 \\
-29 & \pm 64 \\
2 & \pm 6 \\
-14 & \pm 11 \\
9 & \pm 5 \\
-8 & \pm 7 \\
-1 & \pm 10 \\
5 & \pm 13 \\
-11 & \pm 8 \\
-7 & \pm 4 \\
-3 & \pm 4 \\
2 & \pm 4 \\
4 & \pm 4\end{aligned}$ \\
\hline
\end{tabular}

\section{Discussion}

The readings of the chest radiographs of the men in this survey formed a pattern quite characteristic of what would be expected in an old-established industry in which exposure to dust occurred. The distribution of the readings by the categories of the ILO classification has no significance in itself, since it depends as much on the age and stability of the labour force as on the intensity of the exposure to dust. It no longer suggests, however, as could the results reported by Sheers, ${ }^{1}$ that radiological changes characteristic of dust exposure might be restricted to a few men with perhaps unusual working histories. The frequencies in categories $0,1,2$, and 3 form a declining sequence, as would be expected from the usual mode of progression linked with exposure.

In other respects the radiological findings accord with those of Sheers, and quantitative estimates of the rate of development of radiological pneumoconiosis confirm and elaborate his finding of a risk increasing with the dryness of the material handled. The pressmen and firemen before 1954 (job A) whose work began with wet material had a lower regression coefficient than the millers, baggers, and loaders (job B) who worked with the dried material. The same is true of their counterparts after 1954 (jobs C, D, and E), and the difference between the coefficients of $C(16)$ and $D(24)$ is highly significant $(p<0 \cdot 01)$. Sheers, writing in 1961 , also suggested that the then more modern plants and processes were inherently dustier than the older, and this accords with the larger regression coefficient for job $C$ than for job $A$ and for jobs $D$ and $E$ than for job $B$, though these differences could be due to chance.

The regression coefficients are not directly interpretable as they stand (though fig 2 illustrates their meaning), but on the simple model of the severity of the radiological appearance depending on the product of average dust concentration and years of exposure the coefficients should be in proportion to the dust concentrations. Dust sampling has been carried out for several years, and it is understood that the results will be used to make this comparison.

The discovery that the vital capacity shows a small but significant decrease with increasing amount of pneumoconiosis is new. Glover $e^{2} a^{5}$ found that pneumoconiosis in slate workers was associated with a reduction in both FEV and VC, and it now appears that pneumoconiosis in china clay workers resembles this more than pneumoconiosis in coalworkers, where loss of lung function is noticeable only in established massive fibrosis, not in simple pneumoconiosis. Further studies are in progress to discover more about the nature of the loss of ventilatory capacity by using a battery of more searching tests of lung function.

In conclusion, it appears that the alertness of the china clay industry to warnings of a possible hazard associated with dust exposure (Sheers ${ }^{1}$ ), despite the very firm view of its harmlessness usually held (Hunter ${ }^{6}$ ), has enabled preventive measures to be instituted in good time. Regular mass miniature radiographic surveys were conducted in the area of the china clay industry from 1955 onwards, and since 1977 the use of large films has been standard practice. Surveys are now conducted every four years, which, by enabling signs to be detected, should prevent any worker progressing to the higher categories of pneumoconiosis. Very considerable efforts have been put into the suppression and monitoring of dust. This survey can provide no certain evidence that men are progressing in present conditions to disabling levels of pneumoconiosis; all the exposures analysed were of course in the past. The number of agreed cases of massive fibrosis was very small, and all had had long exposure. 
I am indebted to members of the China Clay Industry Dust Prevention Committee for much help, in particular to Mr RA Comyns for preparing the data and clarifying inconsistencies in it, and to Drs Jepson and Sewart for helpful criticism of a draft of this report. I also thank Mr Russell Julian for much helpful information and Drs Gilson, Sheers, and Elmes for reading the chest radiographs.

\section{References}

' Sheers G. Prevalence of pneumoconiosis in Cornish kaolin work- ers. Br J Ind Med 1964;21:218-25.

: International Labour Office. Guidelines for the use of international classification of radiographs of pneumoconiosis. Geneva: ILO, 1980. (Occupational safety and health series No 22 (rev).)

${ }^{3}$ Oldham PD. Numerical scoring of radiological pneumoconiosis. In: Walton WH, ed. Inhaled particles III. Old Woking, Surrey: Unwin, 1971:621-30.

${ }^{4}$ Cole TJ. Linear and proportional regression models in the prediction of ventilatory function. Journal of the Royal Statistical Society. Series A 1975;138:297-338.

s Glover JR, Bevan C, Cotes JE, et al. Effects of exposure to slate dust in North Wales. Br J Ind Med 1980;37:152-62.

"Hunter D. The diseases of occupations. 6th ed. London: Hodder and Stoughton, 1978:1011-2.

\section{Vancouver style}

All manuscripts submitted to the $B r J$ Ind Med should conform to the uniform requirements for manuscripts submitted to biomedical journals (known as the Vancouver style).

The $\mathrm{Br} J$ Ind Med, together with many other international biomedical journals, has agreed to accept articles prepared in accordance with the Vancouver style. The style (described in full in $\mathrm{Br}$ Med J, 24 February 1979, p 532) is intended to standardise requirements for authors.

References should be numbered consecutively in the order in which they are first mentioned in the text by Arabic numerals above the line on each occasion the reference is cited (Manson ${ }^{1}$ confirmed other reports ${ }^{2-5} \ldots$ ). In future references to papers submitted to the $B r J$ Ind Med should include: the names of all authors if there are six or less or, if therc are more, the first three followed by et al; the title of journal articles or book chapters; the titles of journals abbreviated according to the style of Index Medicus; and the first and final page numbers of the article or chapter.

Examples of common forms of references are:

${ }^{1}$ International Steering Committee of Medical Editors. Uniform requirements for manuscripts submitted to biomedical journals. Br Med J 1979;1:532-5.

${ }^{2}$ Soter NA, Wasserman SI, Austen KF. Cold urticaria: release into the circulation of histamine and eosinophil chemotactic factor of anaphylaxis during cold challenge. $N$ Engl J Med 1976;294:687-90.

${ }^{3}$ Weinstein L, Swartz MN. Pathogenic properties of invading micro-organisms. In: Sodeman WA Jr, Sodeman WA, eds. Pathologic physiology: mechanisms of disease. Philadelphia: W B Saunders, 1974:457-72. 